\title{
Predicting the Relative Permeability of Water Phase Based on Theory of Coupled Electricity-Seepage and Capillary Bundle Model
}

\author{
Xinmin Ge ${ }^{1,2, *}$, Yiren Fan ${ }^{1,2}$, Donghui Xing ${ }^{1,2}$, Jingying Chen $^{3}$, Yunhai Cong ${ }^{4}$ and Lailei Liu ${ }^{5}$
}

${ }^{1}$ School of Geosciences in China University of Petroleum, Qingdao 266580, China; ${ }^{2}$ CNPC Key Well Logging Laboratory in China University of Petroleum, Qingdao 266580, China; ${ }^{3}$ Exploration \& Development Research Institute of Petrochina Jidong Oilfield Company, CNPC, Tangshan 063200, China; ${ }^{4}$ Geological Research Institute of Great Wall Drilling Company, CNPC, Panjin 124010, China; ${ }^{5}$ China Petroleum Logging CO. LTD., CNPC, Xi'an 710077, China

\begin{abstract}
An analytical water relative model based on the theory of coupled electricity-seepage and capillary bundle pore structure is described. The model shows that the relative permeability of water is affected by two kinds of parameters, which are depicted as static parameters and dynamic parameters. Revised Kozeny-Carman equation and Archie formulas are introduced to deduce the model, which enhance the characterization ability of pore structure. Two displacing states, where we summarized that oil coats capillary walls and oil occupies capillary centers are also discussed for optimization of the model. In contrast to existing empirical formulas where relative permeability is strongly related to capillary pressure and fractal dimension, we introduce only water saturation and saturation index as input parameters, which make the model simpler to use. Petrophysics and unsteady relative permeability experiments (oil displacing water) are carried out to testify the two models. The fitting results show that for oil displacing experiments presented in this paper, the displacing state where oil coats capillary walls is suitable to predict the relative permeability of water.
\end{abstract}

Keywords: Archie formulas, coupled electricity-seepage, displacing state, relative permeability of water, revised KozenyCarman equation.

\section{INTRODUCTION}

Relative permeability is the ratio of the fluid effective permeability to the absolute permeability, which strongly depends on the saturation and property of fluids in porous media. Relative permeability is a critical parameter in reservoir evaluation, oil \& gas development, etc. Purcell [1] established relative permeability models based on capillary pressure by integral equation method. Burdin [2] modified Purcell model by introducing tortuosity factor of porous media. Corey [3] obtained an analytical solution of relative permeability by analyzing the relationship between capillary pressure and saturation. Prison [4] also established an empirical equation of relative permeability. Brooks et al., [5] revised Corey's model and presented a relative perfect relationship equation between relative permeability and saturation. He et al., [6], and Zhou et al., [7] established relationships among relative permeability, saturation and fractal dimension through fractal theory of porous media. Olafuyi et al., [8] conducted relative permeability experiments after researching small core samples percolation model systematically. Li $[9,10]$ developed relationships among relative permeability, capillary pressure and resistivity index by the similarity of percolation and electricity field in bundle-like porous rock.

From the review of literatures we found that nearly most of relative permeability models presented ever are related to

\footnotetext{
*Address correspondence to this author at the School of Geosciences, China University of Petroleum, Qingdao, China; Tel: +8613646428362;

E-mail: gexinmin2002@163.com
}

capillary pressure data. However, capillary pressure data are also not easy to obtain, and the application of such models is greatly restricted. To overcome these limitations, the paper presents a new model by the theory of coupled electricityseepage and capillary bundle pore structure. We concluded the relative permeability model of water by introducing Kozeny-Carman equation and Archie formulas. The new model incorporates with tortuosity, shape factor, surface volume ratio, etc. We then proposed two ideal displacing states to solve surface volume ratio and to get the analytical solution of the model. We conducted unsteady relative permeability experiments and petrophysics experiments to testify the models.

\section{THEORETICAL APPROACH}

According to Kleinberg et al., [11], the revised KozenyCarman equation of capillary bundle-like porous rock can be expressed as.

$$
K=\frac{\phi}{\nu \tau(A / V)_{\text {grain }}^{2}}
$$

Where $v$ is the shape factor, $(A / V)_{\text {grain }}$ is the ratio of pore surface to volume, $K$ is the absolute permeability of porous rock, $\phi$ is the porosity and $\tau$ is the tortuosity. Formula (1) shows that the absolute permeability in porous rock depends on porosity, pore's connectivity and the contact property between pores and grain.

We introduce capillary bundle model and bulk volume physical model Fig. (1) to simplify the complex pore-grain 
system. Combined with the Archie formulae, the tortuosity is given by Hong [12].

$$
\tau=\left(\frac{L_{w}}{L}\right)^{2}=\frac{R_{o}}{R_{w}} \phi=F \phi
$$

Where $L_{w}$ is the equivalent length of conductive path (or seepage path), $L$ is the length of capillary bundle, $R_{o}$ is the resistivity when rock is fully occupied by water, $R_{w}$ is water resistivity and $F$ is formation factor.

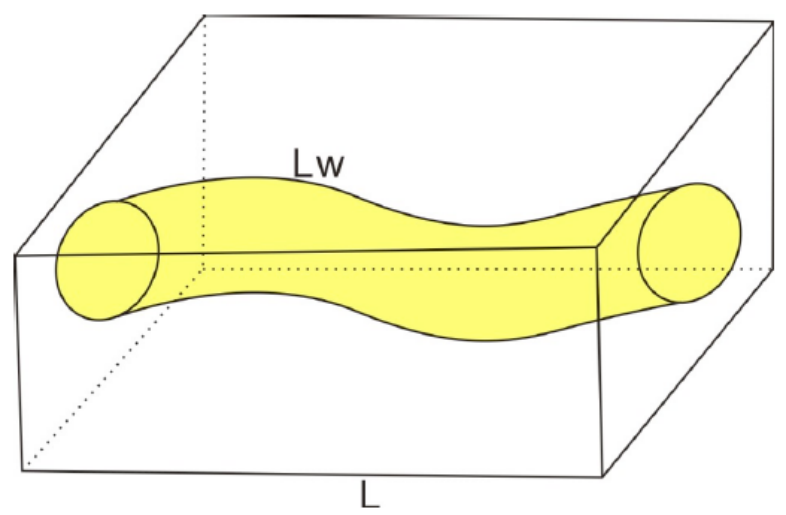

Fig. (1). Physical mode of capillary bundle pore-rock systemCombining Formula (1) and Formula (2), the absolute permeability can be expressed as.

$$
K=\frac{1}{v F(A / V)_{\text {grain }}^{2}}
$$

Two phase (oil and water) percolation problem is discussed in this paper for convenience. Water is the conductive phase and oil is the non-conductive phase. If the shape factor and porosity are constant parameters during the displacing process, the effective permeability of water is given by Formula (4).

$$
K_{w}=\frac{1}{v F_{w}\left(A_{w} / V_{w}\right)_{\text {grain }}^{2}}
$$

Where $F_{w}$ is the apparent formation factor which means formation factor under different water saturation $S_{w}$ is the water saturation and $\left(A_{w} / V_{w}\right)_{\text {grain }}$ is the ratio of pore surface to volume when core is partly saturated with water.

By the definition, the relative permeability is the ratio of effective permeability to absolute permeability. The relative permeability of water is derived by Formula (3) and Formula ().

$$
K_{r w}=\frac{K_{w}}{K}=\frac{F}{F_{w}} \cdot\left(\frac{V_{w}}{V}\right)^{2} \cdot\left(\frac{A}{A_{w}}\right)^{2}
$$

Formula (5) is the new analytical model we presented for the calculation of the relative permeability of water. The relative permeability of water is mainly controlled by two kinds of parameters, where we summarized as static and dynamic parameters. The static parameters are related to porous rock's intrinsic property, such as porosity, the ratio of surface to volume, shape factor, and so on, the dynamic parameters are related to fluid property, such as fluid saturation and displacing state. However, we cannot solve Formula (5) directly without any assumptions.

\section{MODEL SOLUTIONS FOR DIFFERENT DISPLAC- ING STATE}

The ratio of surface to volume under different water saturation, the apparent formation factor under different water saturation and the water saturation are key parameters to obtain the relative permeability of water. We extend the concept of formation factor to get apparent formation factor under different water saturation. The apparent formation factor is defined as ratio of the resistivity of rock when partly saturated with water to the resistivity of water.

$$
F_{w}=\frac{R_{t}}{R_{w}}
$$

Where $R_{t}$ is the resistivity of rock when partly saturated with water, $R_{t}$ is the resistivity of water and $F_{w}$ is the apparent formation factor.

Archie (1942) defined the formation factor as the ratio of the resistivity of rock when fully saturated with water to the resistivity of water.

$$
F=\frac{R_{o}}{R_{w}}
$$

Where $R_{0}$ is the resistivity of rock when fully saturated with water, $R_{w}$ is the resistivity of water and $F$ is the formation factor.

Combing Formula (6) and Formula (7), we can get the ratio of apparent formation factor to formation factor, which can be expressed as:

$\frac{F_{w}}{F}=\frac{R_{t}}{R_{o}}$

It is noted that Formula (8) is a different expression of the Archie formulas. We can reshape Formula (8) to:

$\frac{F_{w}}{F}=\frac{R_{t}}{R_{o}}=\frac{1}{S_{w}^{n}}$

Where $n$ is the saturation index and $S_{w}$ is the water saturation.

$V_{w} / V$ is the ratio of the water volume to the pore volume and can be expressed as:

$\frac{V_{w}}{V}=S_{w}$

Where $V_{w}$ is the water volume and $V$ is the pore volume.

By combination of Formula (9) and Formula (10), the relative permeability of water can be converted to:

$$
K_{r w}=\frac{K_{w}}{K}=S_{w}^{n+2} \cdot\left(\frac{A}{A_{w}}\right)^{2}
$$

For water-oil two phase percolation system, if oil uniformly coats the walls of capillary bundle with the increase 
of oil saturation during the oil displacing process, the radius of the water-filled pore space will be reduced. The pore surface will be occupied mostly by oil with the increase of oil saturation. Fig. (2) depicts the cross section when the displacing reaches steady state. If the radius of capillary bundle is $a$, the radius of water ring in the capillary bundle is $a_{r}$ (where $a_{r}<a$ ), the ratio of the water ring cross section surface area to capillary cross section surface area can be expressed as:

$\frac{A_{w}}{A}=\frac{2 \pi a_{r}}{2 \pi a}=\frac{a_{r}}{a}$

Water saturation in capillary bundle can be expressed as:

$S_{w}=\frac{V_{w}}{V}=\frac{\pi a_{r}^{2} L}{\pi a^{2} L}=\frac{a_{r}^{2}}{a^{2}}$

Substituting Formula (13) into Formula (12), the ratio of the water ring cross section surface area to capillary cross section surface area can be revised to:

$\frac{A_{w}}{A}=S_{w}^{0.5}$

Combing Formula (14) and Formula (11), we have:

$K_{r w}=\frac{K_{w}}{K}=S_{w}^{n+1}$

Formula (15) is the water phase relative permeability model when oil coats capillary walls during the oil displacing water process.

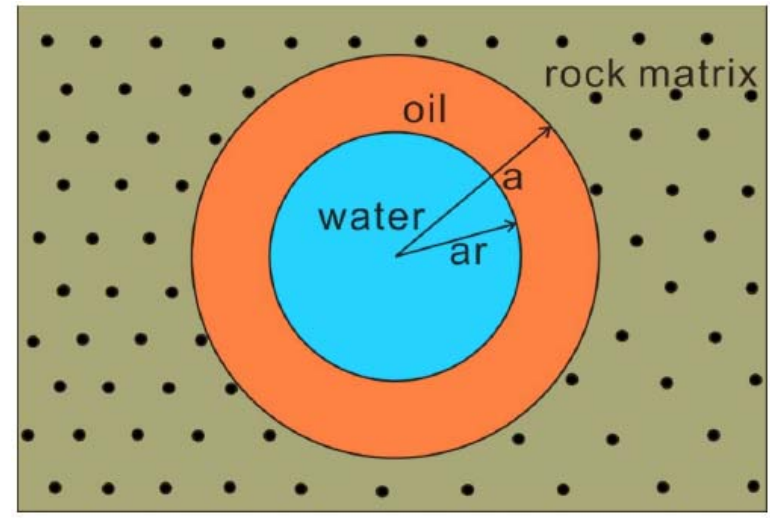

Fig. (2). Cross section parameters of capillary model when oil coats capillary walls.

If oil is mostly occupies the capillary centers during the oil displacing process, the water will be distributed in the space between capillary wall and oil ring. Fig. (3) is the cross section when the displacing reaches steady state. If the radius of capillary bundle is $a$, the radius of oil ring in the capillary bundle is $a_{r}$ (where $\left.a_{r}<a\right)$, the water saturation can be expressed as:

$S_{w}=\frac{V_{w}}{V}=\frac{\pi a^{2} L-\pi a_{r}^{2} L}{\pi a^{2} L}=1-\left(\frac{a_{r}}{a}\right)^{2}$

Where $V_{w}$ is the water volume, $V$ is the pore volume and $L$ is the length of capillary bundle.

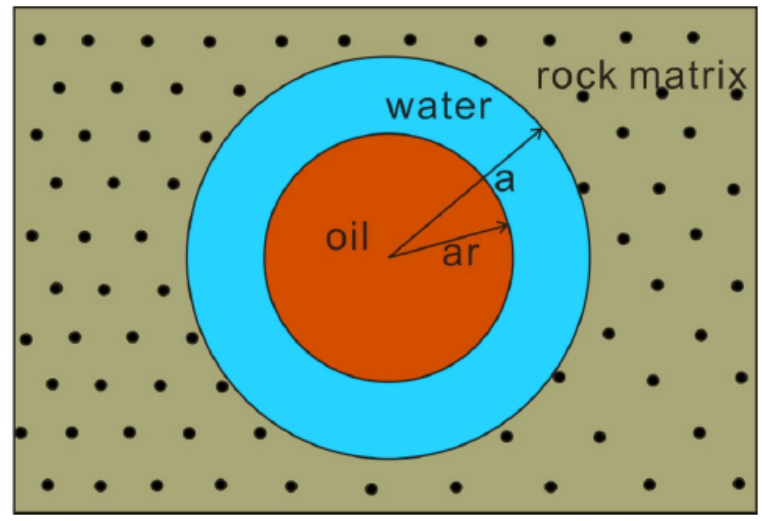

Fig. (3). Cross section parameters of capillary model when water coats capillary walls.

The ratio of the water ring cross section surface area to capillary cross section surface area can be expressed as:

$\frac{A_{w}}{A}=\frac{2 \pi\left(a+a_{r}\right)}{2 \pi a}=\frac{a+a_{r}}{a}=\left(1+\left(1-S_{w}\right)^{0.5}\right)$

Where $A_{w}$ is the water ring cross section surface area and $A$ is the capillary cross section surface area.

The ratio of the water ring cross section surface area to capillary cross section surface area is higher when the oil is occupies the capillary centers than the oil coats the capillary walls.

Substituting Formula (16) and Formula (17) to Formula (11), when oil occupies capillary centers during the oil displacing process, the relative permeability of water can be expressed as.

$$
K_{r w}=\frac{K_{w}}{K}=S_{w}^{n+2} \cdot \frac{1}{\left(1+\left(1-S_{w}\right)^{0.5}\right)^{2}}
$$

FormulaFormula (15) and Formula (18) are two relative permeability models of water under different displacing state with the theory of coupled electricity-seepage and capillary bundle pore structure. Whereas displacing states, the relative permeability of water only relates to water saturation and saturation index, which is simpler than ever.

\section{EXPERIMENTS AND DISCUSSIONS}

Four shaly sand cores were selected from $G$ oilfield in northern China. We use oil displacing method to get the relative permeability of water and the resistivity under different water saturation. Least square method was used to fit the saturation index of each core. Table $\mathbf{1}$ is the basic parameters of cores. The porosity ranges from $7.49 \%$ to $23.4 \%$ the permeability ranges from $0.524 \times 10^{-3} \mu \mathrm{m}^{2}$ to $359 \times 10^{-3} \mu \mathrm{m}^{2}$ and the saturation index ranges from 1.532 to 1.736 . The salinity and viscosity of water used in the experiment are $20 \mathrm{~g} / \mathrm{l}$ and $0.552 \mathrm{mPa}$.s separately. The viscosity of oil is 6.104mPa.s. All the experiments were carried out under room temperature (20 centigrade).

Figs. (4-7) Show comparisons between the measured data and the fitted data of models, and the error bars of the two models we presented. The black points are measured data, 
Table 1. Basic property of samples.

\begin{tabular}{|c|c|c|c|c|}
\hline Sample & Lithology & $\mathbf{\phi} \%$ & $\mathbf{K} / \mathbf{1 0} \mathbf{\mu m}^{\mathbf{2}}$ & $\mathbf{n}$ \\
\hline \hline 1 & Shaly Sand & 23.4 & 359 & 1.736 \\
\hline 2 & Shaly Sand & 22.5 & 1.58 & 1.54 \\
\hline 3 & Shaly Sand & 15.2 & 0.524 & 1.532 \\
\hline 4 & Shaly Sand & 7.49 & & 1.54 \\
\hline
\end{tabular}

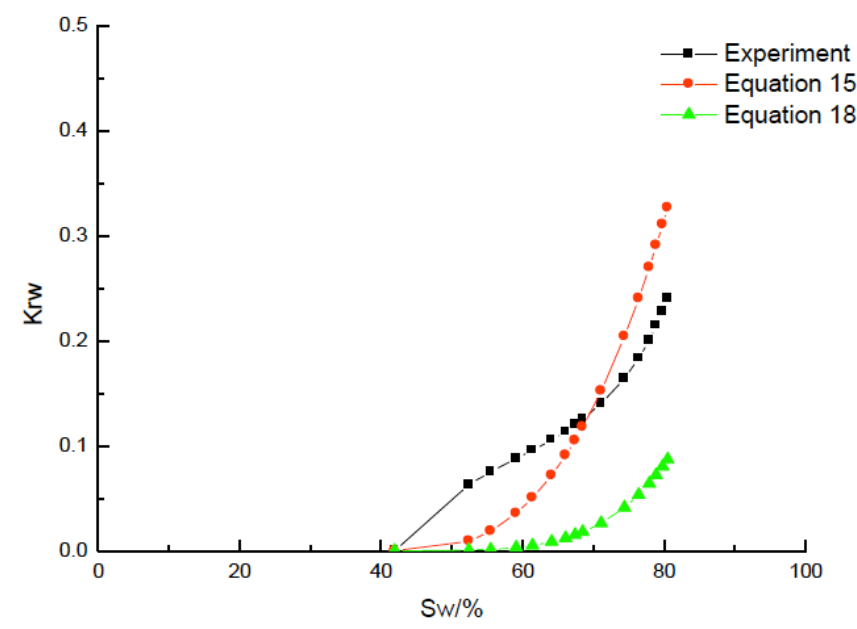

(a) The relative permeability and saturation of water

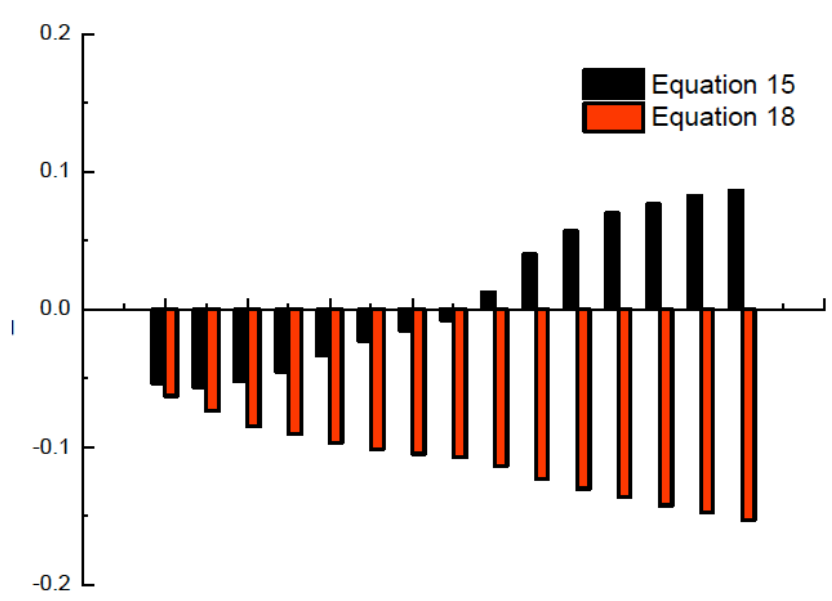

(b) Error bars

Fig. (4). Relationship between the relative permeability and saturation of water, and the error bars for core sample 1.

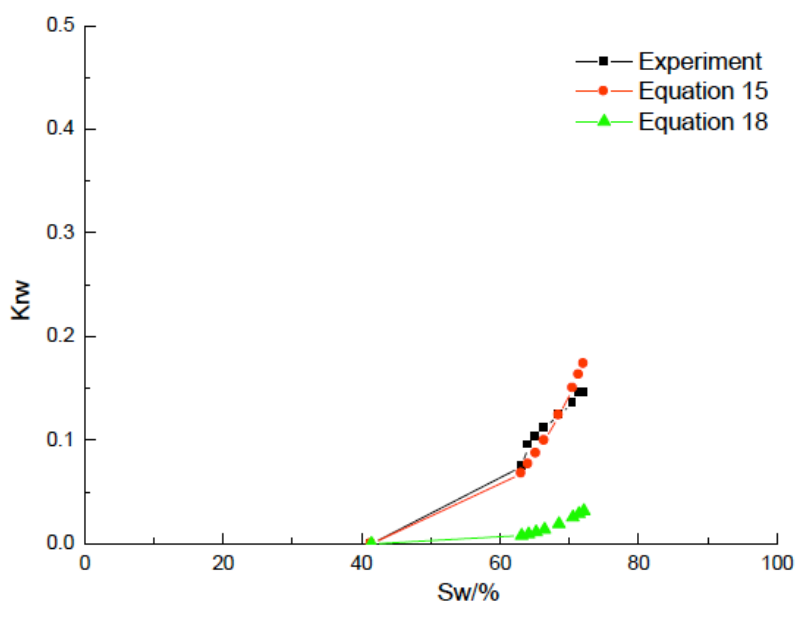

(a) The relative permeability and saturation of water

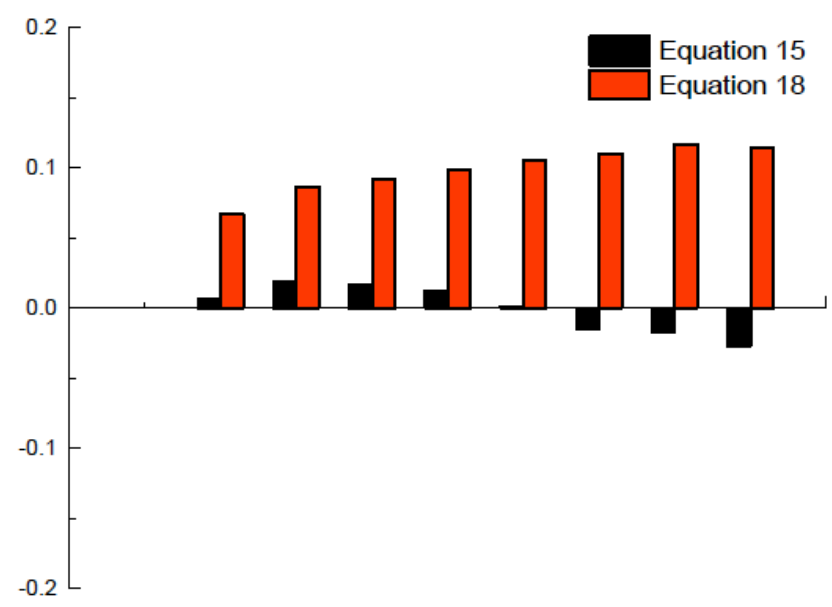

(b) Error bars

Fig. (5). Relationship between the relative permeability and saturation of water, and the error bars for core sample 1.

the red points and lines are fitting curves and data by Formula (15) and the blue points and lines are fitting curves by Formula (18). The relative permeability of water is positively correlated with the water saturation. The data fitted by Formula (15) is more precise than that fitted by Formula (18). The mean square error of data fitted by Formula (15) is 0.0454 , whereas 0.0857 for the data fitted by Formula (18). The oil is prone to coat the capillary walls during the oil dis- placing process. It is noted that large deviation can be observed between the measured data and the fitted data in some cases, which can be explained that the ideal capillary bundle and fluid distributing state can not simulate the actual pore structure and fluid seepage law completely. However, the relative permeability of water can be obtained if there is few experimental data. 


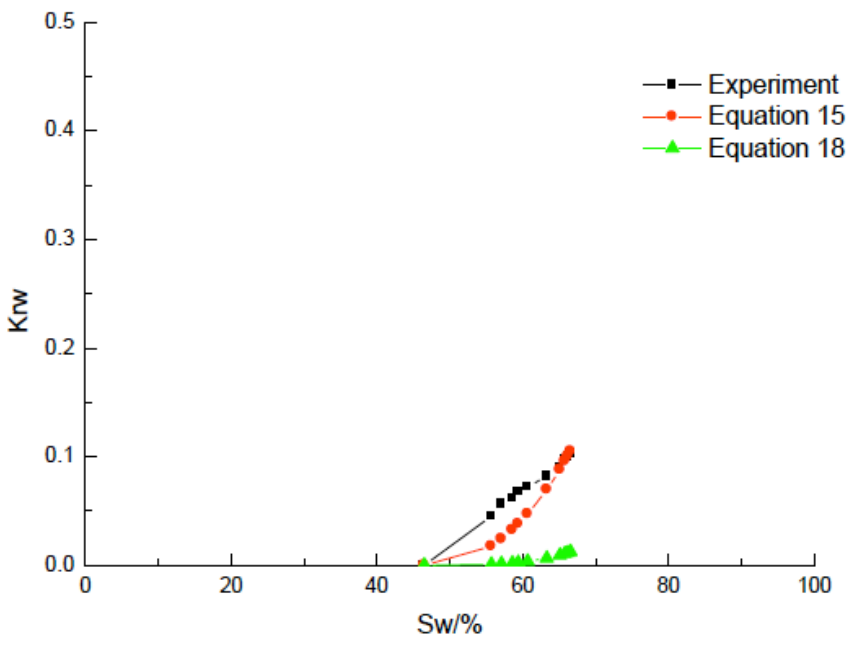

(a) The relative permeability and saturation of water

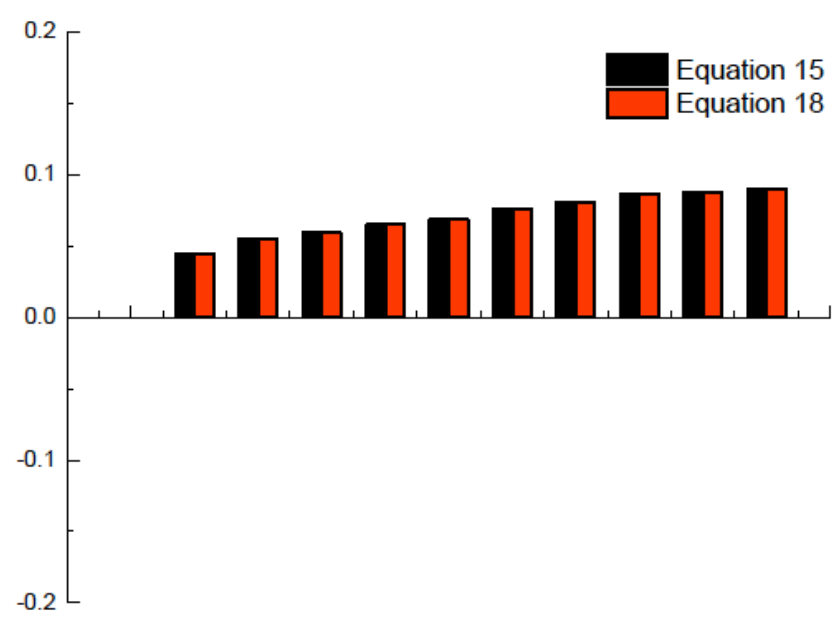

(b) Error bars

Fig. (6). Relationship between the relative permeability and saturation of water, and the error bars for core sample 1 .

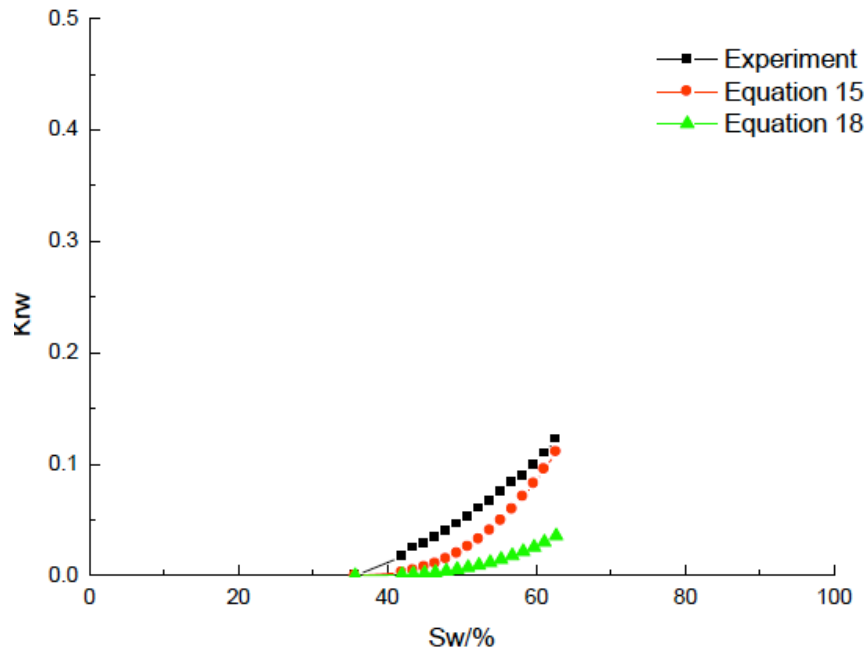

(a) The relative permeability and saturation of water

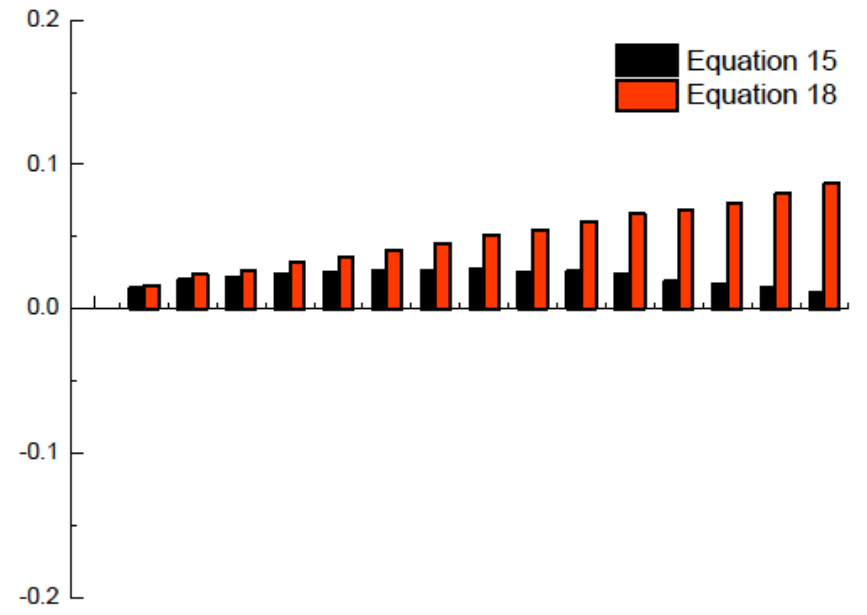

(a) Error bars

Fig. (7). Relationship between the relative permeability and saturation of water for core sample 4.

\section{CONCLUSION}

This paper has outlined a new methodology to predict the relative permeability of water with the theory of coupled electricity-seepage and capillary bundle pore structure model. It is observed that the pore structure and fluid distribution state bear direct relation to the relative permeability of water.

Tortuosity and water saturation were introduced to deduce the relationship between relative permeability and resistivity. Using capillary bundle model and Archie formulas, the ratio of apparent formation factor to formation factor $(\mathrm{Fw} / \mathrm{F})$ and the ratio of the water ring cross section surface area to capillary cross section surface area (Aw/A) were defined, which related to the oil displacing state.

The new analytical relative permeability model of water was introduced after the ratio of apparent formation factor to formation factor $(\mathrm{Fw} / \mathrm{F})$, the ratio of the water ring cross section surface area to capillary cross section surface area (Aw/A), saturation and saturation index were elaborated.
Compared with models in literatures, the new model is just the function of saturation and saturation index, which bears no relation to capillary pressure and fractal dimension. The experiments and fitting results show that oil is likely to coats the capillary grain and water is more likely to coats the capillary center during oil displacing water process.

\section{CONFLICT OF INTEREST}

The authors confirm that this article content has no conflict of interest.

\section{ACKNOWLEDGEMENTS}

The work was supported by the National Natural Science Foundation of China (41404086), Natural Science Foundation of Shandong Province, China (ZR2014DQ007), China Postdoctoral Science Foundation (2014M560591), Major National Science and Technology Projects of China (2011ZX05020-008), National Key Foundation for Exploring Scientific Instrument of China (2013YQ170463) and 
CNPC Scientific Research and Technology Development Project (2012E-34-12, 2014D-0907).

\section{REFERENCES}

[1] W.R. Purcell, "Capillary pressures-their measurement using mercury and the calculation of permeability," Journal of Petroleum Technology, vol. 1, no. 2, pp. 39-46, 1949.

[2] N.T. Burdine, "Relative permeability calculations from pore size distribution data," Transaction of AIME, vol. 5, no. 3, pp. 71-78, 1953.

[3] A.T. Corey, "The interrelation between gas and oil relative permeabilities," Prod. Mon., vol. 19, no. 1, pp. 38-41, 1954.

[4] S.J. Pirson, Ed., Oil Reservoir Engineering. McGraw-Hill: New York, 1958.

[5] R.H. Brooks. and A.T. Corey, "Properties of porous media affecting fluid flow," Journal of the Irrigation and Drainage Division, vol. 92, pp. 61-88, 1966.

[6] Y. He, Y. Wu, and N. Wu, "A new method for measuring the relative permeability quantitatively," Petroleum Exploration and Development (in Chinese), vol. 27, no. 5, pp. 66-68, 2000.
[7] K. Zhou, Q. Zhang, Q. Wang, and Y. Yan, and N. Li, "Calculation of gas and water relative permeability by the fractal model," Natural Gas Industry (in Chinese), vol. 27, no. 10, pp. 88-89, 2007.

[8] O.A. Olafuyi, Y. Cinar, M.A. Knackstedt, and W. V. Pinczewski, "Capillary pressure and relative permeability of small cores," In: SPE/DOE Symposium on Improved Oil Recovery, SPE11386, Tulsa, Oklahoma, USA, 2008.

[9] K. Li, "A new method for calculating two-phase relative permeability from resistivity data in porous media," Transport in Porous Media, vol. 74, no. 1, pp. 21-33, 2008.

[10] Kewen, Li, "Interrelationship between resistivity index, capillary pressure and relative permeability," Transport in Porous Media, vol. 88, no. 3, pp. 385-398, 2011.

[11] R.L. Kleinberg, C. Flaum, D.D. Griffin, P.G. Brewer, G.E. Malby, E.T. Peltzer and J.P. Yesinowski, "Deep sea NMR: Methane hydrate growth habit in porous media and its relationship to hydraulic permeability, deposit accumulation, and submarine slope stability, Journal of Geophysical Research, vol. 108, no. B10, 2003.

[12] Y. Hong, Well Logging Principle and Comprehensive Analysis (in Chinese). China University of Petroleum Press: Dongying, 2005.

(C) Ge et al.; Licensee Bentham Open.

This is an open access article licensed under the terms of the Creative Commons Attribution Non-Commercial License (http://creativecommons.org/licenses/by-nc/3.0/) which permits unrestricted, non-commercial use, distribution and reproduction in any medium, provided the work is properly cited. 